\title{
Optimal Load Distribution of Thermal Generating Units using Particle Swarm Optimization (PSO)
}

\author{
Abhinav Saxena, G.M Patil, Prashant, Parveen Poon Terang, Nirmal kumar Agarwal, Arun \\ Rawat
}

\begin{abstract}
This paper shows load planning of two thermal generating units feeding a load of $200 \mathrm{MW}$ using Particle swarm optimization (PSO). The PSO involves selection of population size or number of particle, fitness function. The advantages of PSO over conventional method are better and reliable solution, better convergence rate. Initially fitness function, population size corresponding to each variable are decided, thereafter PSO is used for finding most optimal solution of the generating units under different set of iteration. The performance of system using PSO is compared with conventional method in terms of the tolerance band.
\end{abstract}

Index Terms: PSO, fitness, population size, thermal.

\section{INTRODUCTION}

In a thermal power station, as its suggest heat or steam energy is used to generate electrical energy using inverse electromagnetic conversion. Generally, steam turbines are used to drive the synchronous generator at synchronous speed. Steam can be used after it has passed through the turbine by means of a condenser. This process of steam recycling popularly called is known as Rankine Cycle. The division of thermal power stations into various designs is done mainly on the basis of source of heat used for power generation. While fossil fuels are most commonly used, some modern thermal generating units deploy the use of nuclear and solar forms of energy for heat generation. Thermal power stations are sometimes also referred to as 'energy centers' because they convert heat energy into electrical energy. Thermal power stations are designed in such a way that they can also be used to generate heat energy for industrial purposes such as District Heating and Desalination of water [1]

For optimum operation of power plants, it is required to find the optimum parameter of the system with the minimum cost for maximum output ratio. This is processed to consider the financial and economic aspects of the system with different set of optimized iteration levels until desired solution is obtained. Economic Load Dispatch (ELD) is a optimized process which has been in use since the 1951 s for finding the

Revised Manuscript Received on July 5, 2019.

Abhinav Saxena, Ph.D. scholar, Electrical Engineering from Jamia Millia Islamia, India, abhinaviitroorkee@gmail.com

G.M Patil, JSS Science and Technology University, Mysuru, India

Prashant, PhD scholar at Department of Electrical Engineering, Jamia Millia Islamia, New Delhi, India

Parveen Poon Terang,

Nirmal kumar Agarwal, Assist. Prof. in Electrical Engg. Deptt. at JSSATE Noida (UP).

Arun Rawat, JSS Science and Technology University, Mysuru, India perfect operational scheme for the operation of power plants to meet the specified load requirements dynamically[2,3] and to save environment from pollution. ELD is performed by using a different number of methods such as, Fuzzy logic controller, ANN etc.

\section{PARTICLE SWARM OPTIMIZATION (PSO)}

Particle swarm optimization (PSO) follows the nature of colonies such as swarm of insects, flock of birds, ants, bees, etc $[5,6,7,8,9]$. The particle represents bee in the colony etc. which uses its own intelligence in search of target while other particles follow the path of target given by adjacent particle. Swarm represents the searching of food or target in a group. The swarm is assumed to be of specific size in a multidimensional search space $[10,11,12,13,14,15,19]$. Each particle has two properties: position and velocity. PSO concept was given by Kennedy and Eberhart in 1995

Each particle searches for best position and velocity in search of design space. It is given as

$$
\begin{aligned}
& V_{j}(i)=V_{j}(i-1)+c_{1} r_{1}\left[P_{\text {best } j}-X_{j}(i-1)\right]+ \\
& c_{2} r_{2}\left[G_{\text {best }}-X_{j}(i-1)\right]
\end{aligned}
$$

$X_{j}=X_{j}(i-1)+V_{j}(i)$

Where: $\mathrm{G}_{\text {best }}=$ Global Best Position.

$\mathrm{P}_{\text {best }}=$ Self Best Position.

$\mathrm{C}_{1}$ and $\mathrm{C}_{2}=$ Acceleration Coefficients.

$\mathrm{V}_{\mathrm{j}}(\mathrm{i})=$ Velocity of $\mathrm{j}^{\text {th }}$ of $\mathrm{i}^{\text {th }}$ iteration.

$X_{j}=$ Particle of $j^{\text {th }}$ of $i^{\text {th }}$ iteration.

$\mathrm{j}=$ Number of particle

$\mathrm{i}=$ iteration

$\mathrm{X}_{\mathrm{j}}(\mathrm{i})=\mathrm{X}_{\mathrm{j}}(\mathrm{i}-1)+\mathrm{V}_{\mathrm{j}}(\mathrm{i})$

$r_{1}$ and $r_{2}$ are random variables which lie between 0 and 1 .

\section{THERMAL GENERATING UNITS:}

Fig.1 shows the structure of three thermal generating units feeding the load of $200 \mathrm{MW}$ through grid connected system. The cost characteristic of thermal power plant varies quadratically with respect to generating units and can be expressed by 


$$
\begin{aligned}
F_{i}\left(P_{i}\right) & =a P_{i}^{2}+b P_{i}+c \mathrm{Rs} / \mathrm{h} \\
& =F_{1}\left(P_{1}\right)+F_{2}\left(P_{2}\right)
\end{aligned}
$$

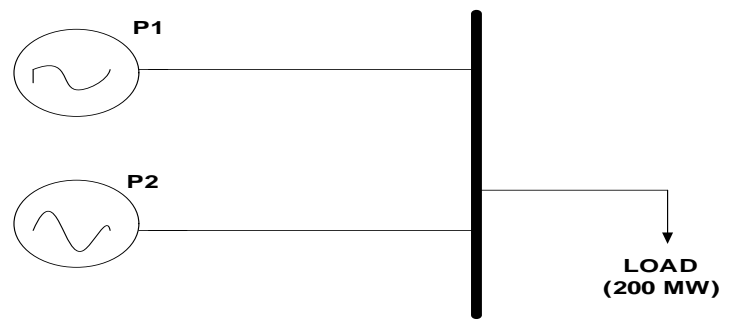

Fig.1 Structure of 2 generating units feeding a load of 200MW

Two generating units namely $P_{1}, P_{2}$ are of rating 200, $150 \mathrm{MW}$ respectively under the constraints as

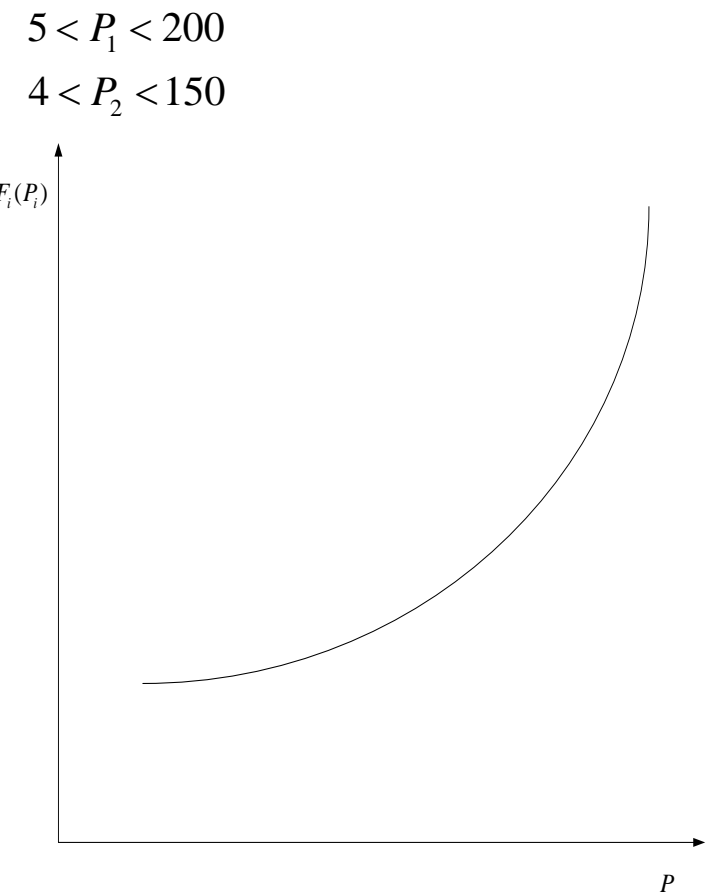

Fig.2.Variation of cost characteristic w.r.t generating unit

Differentiate Eq. (1) w.r.t to $\mathrm{P}_{\mathrm{i}}$

$\frac{d\left(F_{i}\left(P_{i}\right)\right)}{d\left(P_{i}\right)}=2 a P_{i}+b$

On solving Eq.(3) and (4) with some approximation on hit and trail method. It is easy to solve for the value of $a, b, c$ for three generating units and it is given as

$F_{1}\left(P_{1}\right)=0.04 P_{1}^{2}+1.71 P_{1}+191$

$F_{2}\left(P_{2}\right)=0.05 P_{2}^{2}+10.72 P_{2}+217$

Transmission line losses are given by

$$
P_{L}=\sum_{i=1}^{3} \sum_{j=1}^{3} P_{i} P_{j} B_{i j}
$$

Loss coefficient for the system is

$B_{i j}=\left|\begin{array}{ccc}0.0025 & 0.00030 & 0.00251 \\ 0.0017 & 0.0087 & 0.00912 \\ 0.0068 & 0.0089 & 0.00792\end{array}\right|$

\section{CONVENTIONAL METHOD :}

In Conventional method, the economic load scheduling for equalizing incremental fuel cost is given as:

$$
\begin{aligned}
& L_{1} \frac{d\left(F_{i}\left(P_{i}\right)\right)}{d\left(P_{1}\right)}=L_{2} \frac{d\left(F_{i}\left(P_{i}\right)\right)}{d\left(P_{2}\right)} \\
& L_{1}=\frac{1}{\left(1-\frac{\partial P_{L}}{\partial P_{1}}\right)} \\
& L_{2}=\frac{1}{\left(1-\frac{\partial P_{L}}{\partial P_{2}}\right)} \\
& P_{D}+P_{L}=\sum_{i=1}^{2} P_{i}
\end{aligned}
$$

Tolerance or converging limit

$$
\varepsilon=P_{D}+P_{L}-\sum_{i=1}^{2} P_{i}
$$

On solving Eq. $(5,6,7,8,9,10,11)$, the solution obtained is:

$$
\begin{aligned}
& P_{1}=150 \mathrm{MW}, P_{2}=63 \mathrm{MW} \\
& P_{D}=200 \mathrm{MW}, P_{L}=16 \mathrm{MW}
\end{aligned}
$$

From this tolerance limit from Eq. (12) is $\varepsilon=3$

Which is quite far above the acceptable limit. The acceptable is:

$\varepsilon \leq 0.1$

The calculated tolerance limit is not lying in the acceptable range. 


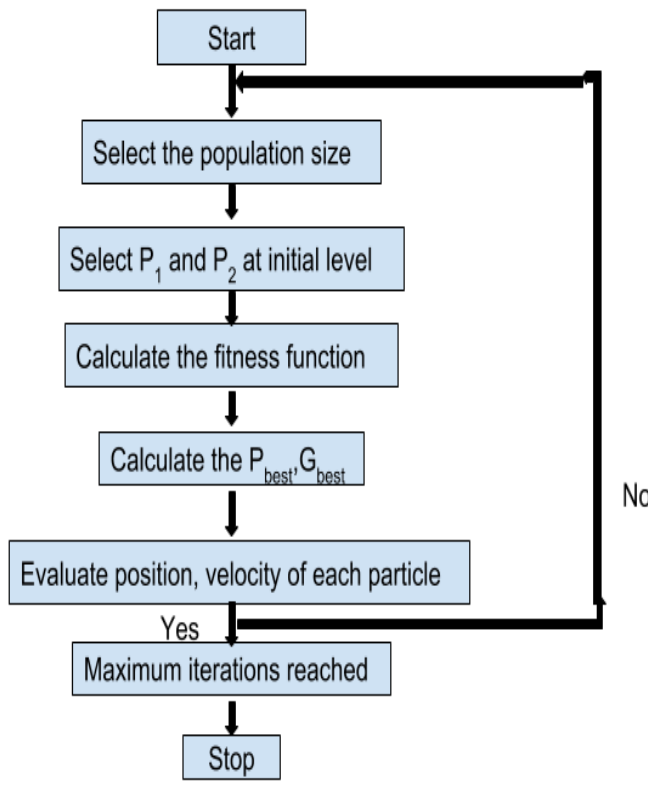

Fig.3. Flowchart representing the GAs for economic Scheduling for three thermal scheduling

\section{APPLICATION OF PSO IN GENERATING} UNITS

Let apply the concept of PSO in economic scheduling

$\mathrm{F}_{1}\left(\mathrm{P}_{1}\right)=0.04 \mathrm{P}_{1}^{2}+1.71 \mathrm{P}_{1}+191$

$\mathrm{F}_{2}\left(\mathrm{P}_{2}\right)=0.05 \mathrm{P}_{2}^{2}+10.72 \mathrm{P}_{2}+217$

$5<\mathrm{P}_{1}<200$

$4<\mathrm{P}_{2}<150$

Take 4 particles and initial population for generating units

$\mathrm{P}_{1,1}=12 \mathrm{MW} \quad \mathrm{P}_{1,2}=94 \mathrm{MW}$

$\mathrm{P}_{2,1}=18 \mathrm{MW} \quad \mathrm{P}_{2,2}=39 \mathrm{MW}$

$\mathrm{P}_{2,3}=59 \mathrm{MW} \quad \mathrm{P}_{2,4}=94 \mathrm{MW}$

Choose $r_{1}=r_{2}=0.5$

$\mathrm{C}_{1}=0.7$

$\mathrm{C}_{2}=0.9$

Load demand, $\mathrm{P}_{\mathrm{D}}=200 \mathrm{MW}$

Table.1. Generating units for initial iteration

\begin{tabular}{|c|c|c|}
\hline $\begin{array}{c}\text { Population } \\
\text { size particle }\end{array}$ & $\mathbf{P}_{\mathbf{1}}$ & $\mathbf{P}_{\mathbf{2}}$ \\
\hline 1 & 12 & 18 \\
\hline 2 & 56 & 39 \\
\hline 3 & 78 & 59 \\
\hline 4 & 94 & 72 \\
\hline
\end{tabular}

Table.2. Generating units for first iteration

\begin{tabular}{|c|c|c|}
\hline $\begin{array}{c}\text { Population } \\
\text { size particle }\end{array}$ & $\mathbf{P}_{\mathbf{1}}$ & $\mathbf{P}_{\mathbf{2}}$ \\
\hline 1 & 10.25 & 83.5 \\
\hline
\end{tabular}

\begin{tabular}{|c|c|c|}
\hline 2 & 86.1 & 114.9 \\
\hline 3 & 91.5 & 109.5 \\
\hline 4 & 187.5 & 13.5 \\
\hline
\end{tabular}

Table.3: Generating units for $12^{\text {th }}$ iteration

\begin{tabular}{|c|c|c|}
\hline $\begin{array}{c}\text { Population } \\
\text { size particle }\end{array}$ & $\mathbf{P}_{\mathbf{1}}$ & $\mathbf{P}_{\mathbf{2}}$ \\
\hline 1 & 137.41 & 83.5 \\
\hline 2 & 99.41 & 114.9 \\
\hline 3 & 141.61 & 109.5 \\
\hline 4 & 121.61 & 13.5 \\
\hline
\end{tabular}

Table.4: Generating units for $39^{\text {th }}$ iteration

\begin{tabular}{|l|l|l|}
\hline $\begin{array}{l}\text { Population size } \\
\text { particle }\end{array}$ & $\mathrm{P}_{1}$ & $\mathrm{P}_{2}$ \\
\hline 1 & 118.5 & 81.6 \\
\hline 2 & 118.5 & 81.9 \\
\hline 3 & 118.6 & 82.1 \\
\hline 4 & 119.5 & 82.2 \\
\hline
\end{tabular}

It is observed that generating units $P_{1}, P_{2}$ converges to approximately same value after the 39 iteration.

$$
\begin{aligned}
& P_{1}=118 M W \\
& P_{2}=82 M W
\end{aligned}
$$

Eq.(12) shows tolerance or convergence limit under genetic algorithm for different set of iteration level(k)

At 39th iteration, some better results is obtained as shown in Fig. 5 and its tolerance or convergence limit. $\varepsilon^{39}=0.00721$

It is lying within the acceptable limit for

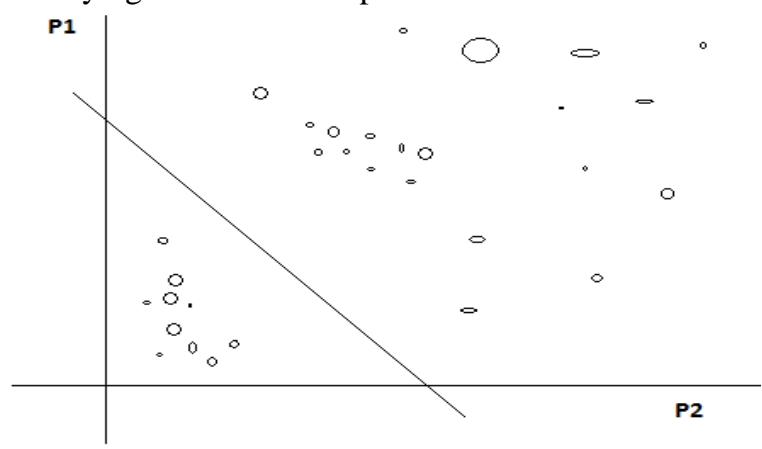

Fig.4. Regression Analysis for initial iteration 


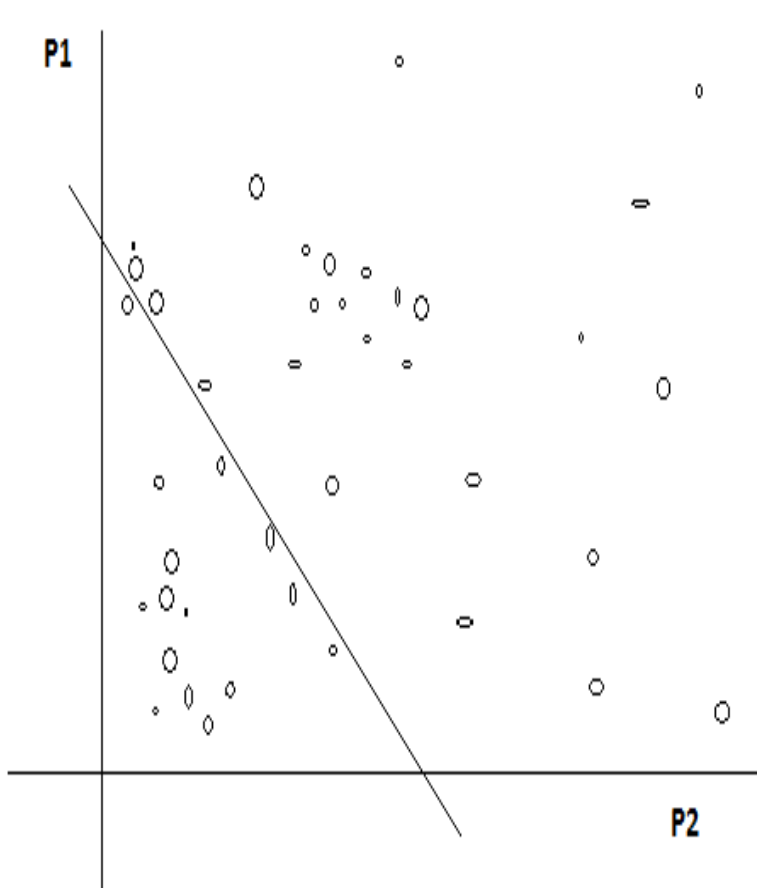

Fig.5. Regression Analysis for $12^{\text {th }}$ iteration

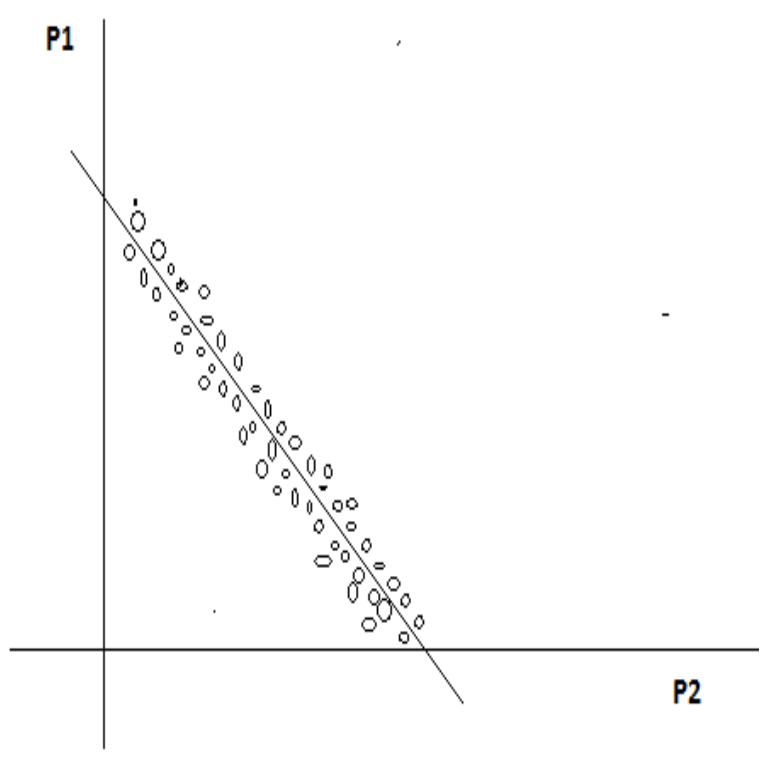

Fig.6. Regression Analysis for $39^{\text {th }}$ iteration

Fig.4,5,6 shows the regression analysis of 2 generating units using PSO for checking the tolerance limit. It is observed that during iteration generating units are so much diverging in nature.

As iteration level increases generating units are approaching to each other towards regression line. But at the end of 39th iteration clustering of all generating units are very close to each other as shown in Fig.6 which shows the converging nature in acceptable range.

\section{CONCLUSION}

This paper shows the optimum load planning of two generating units feeding load of $200 \mathrm{MW}$ using particle swarm optimization (PSO). Under process PSO system consisting of different generating units is converging after attaining the particular iteration. It is found that Thermal generating units gives the better output using PSO in comparison to conventional method in terms of better tolerance band. The Application of PSO makes the system more converging, reliable and efficient for selecting the different generating units to satisfy load demand of $200 \mathrm{MW}$

\section{REFERENCES}

1. Jichun Liu, Member, IEEE and Jie Li, Member, IEEE,' Interactive Energy-Saving Dispatch Considering Generation and Demand Side Uncertainties: A Chinese Study', DOI 10.1109/TSG.2016.2623947,IEEE Transactions on Smart Grid,2018

2. Morteza Nojavan, Heresh Seyedi,' Voltage stability margin improvement using hybrid non-linear programming and modified binary particle swarm optimisation algorithm considering optimal transmission line switching', IET Generation, Transmission \& Distribution, 2018

3. Mahari, A., Seyedi, H.: 'A wide area synchrophasor-based load shedding scheme to prevent voltage collapse', Int. J. Electric. Power Energy Syst.,78, (1), pp. 248-257,2016

4. Saffarian, A., Sanaye-Pasand, M.: 'Enhancement of power system stability using adaptive combinational load shedding methods', IEEE Trans. Power Syst., 2011, 26, (3), pp. 1010-1020

5. Arya, L.D., Singh, P., Titare, L.S.: 'Differential evolution applied for anticipatory load shedding with voltage stability considerations', Int. J. Electric. Power Energy Syst.,42, (1), pp. 644-652,2012

6. Verbic, G., Gubina, F.: 'A new concept of protection against voltage collapse based on local phasors'. Int. Conf. Power System Technology, pp. 965- 970,2000

7. Šmon, I., Pantoš, M., Gubina, F.: 'An improved voltage-collapse protection algorithm based on local phasors', Electr. Power Syst. Res. 2008, 78, (3), pp. 434-440

8. Rabiee, A., Parvania, M., Vanouni, M., et al.: 'Comprehensive control framework for ensuring loading margin of power systems considering demand-side participation', IET. Gener. Transm. Distrib.6, (12), pp. 1189-1201,2012

9. Titare, L.S., Singh, P., Arya, L.D., et al.: 'Optimal reactive power rescheduling based on EPSDE algorithm to enhance static voltage stability', Int. J. Electric. Power Energy Syst.,63, (1), pp. 588-599,2014

10. Mohseni-Bonab, S.M., Rabiee, A., Mohammadi-Ivatloo, B.: 'Voltage stability constrained multi-objective optimal reactive power dispatch under load and wind power uncertainties: a stochastic approach', Renew. Energy, 85, (1), pp. 598-609,2016

11. Karbalaei, F., Kalantar, M., Kazemi, A.: 'On line diagnosis of capacitor switching effect to prevent voltage collapse', Energy Convers. Manage.,51, (11), pp. 2374-2382,2010

12. Raoufi, H., Kalantar, M.: 'Reactive power rescheduling with generator ranking for voltage stability improvement', Energy Convers. Manage., 50, (4), pp. 1129-1135,2009

13. Rolim, J.G., Machado, L.J.B.: 'A study of the use of corrective switching in transmission systems', IEEE Trans. Power Syst., 1999 14, (1), pp. 336-341

14. Wu, J., Cheung, K.W.: 'On selection of transmission line candidates for optimal transmission switching in large power networks'. Power and Energy Society General Meeting, 2013

15. Shao, W., Vittal, V.: 'Corrective switching algorithm for relieving overloads and voltage violations', IEEE Trans. Power Syst., 2005, 20, (4), pp. 1877- 1885

16. Shao, W., Vittal, V.: 'A new algorithm for relieving overloads and voltage violations by transmission line and bus-bar switching'. Power Systems Conf. and Exposition, 2004

17. Wang, X., Shao, W., Vittal, V.: 'Adaptive corrective control strategies for preventing power system blackouts'. 15th Power Systems Computation Conf., Liège, Belgium, 2005 
18. Shao, W., Vittal, V.: 'BIP-based OPF for line and bus-bar switching to relieve overloads and voltage violations'. Power Systems Conf. and Exposition, 2006

19. Gou, B., Zhang, H.: 'Fast real-time corrective control strategy for overload relief in bulk power systems', IET. Gener. Transm. Distrib. 2013, 7, (12), pp. 1508-1515

20. Lobato, E., Echavarren, F., Rouco, L., et al.: 'A mixed-integer lp based network topology optimization algorithm for overload alleviation'. Power Tech Conf. Proc., 2003

21. Arya, L.D., Choube, S.C., Kothari, D.P.: 'Line switching for alleviating overloads under line outage condition taking bus voltage limits into account', Int. J. Electric. Power Energy Syst., 2000, 22, (3), pp. 213-221

22. Granelli, G., Montagna, M., Zanellini, F., et al.: 'Optimal network reconfiguration for congestion management by deterministic and genetic algorithms', Electr. Power Syst. Res., 2006, 76, (6), pp. 549-556

23. Lalwani, S., Kumar, R., Gupta, N.: 'A novel two-level particle swarm optimization approach to train the transformational grammar based Hidden Markov models for performing structural alignment of pseudoknotted RNA', Swarm Evol. Comput., 2015, 20, (1), pp. 58-73

\section{AUTHORS PROFILE}

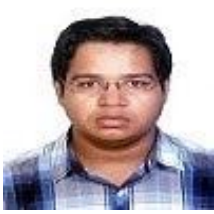

Abhinav Saxena received the B.Tech.Degree in Electrical Engineering from U.P.T.U Lucknow in 2011 and M.Tech.from IIT Roorkee in 2013.Currently he is pursuing Ph.D. in Electrical Engineering from Jamia Millia Islamia, India. His research areas include Power Electronics, Electrical Machines, Power System, Control System and Intelligent Techniques, Renewable energy

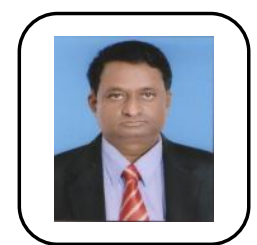

Dr. Gurulingappa M. Patil. Bachelor of Engineering from Sri.Jayachamarajendra Colleg of Engineering Mysore in 1984. Master of Engineering from Indian Intitute of Technology, Roorkee, in 1990. Ph. D. from University College of Engineering, Osmania University, Hyderabad, in February, 2011. He has more than 35 research paper. His research areas are biomedical $\&$ bioinstrumentation engineering

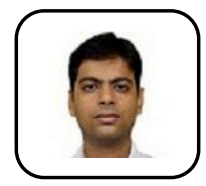

Mr. Prashant is $\mathrm{PhD}$ scholar at Department of Electrical Engineering, Jamia Millia Islamia, New Delhi. His research area of Interest are Power System, Restructuring and Deregulation of Power System, Solar Photovoltaic Systems, Renewable Energy, \& application of intelligent techniques in power system operations.

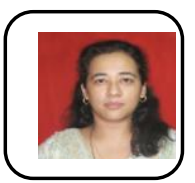

Dr. Parveen Poon Terang (MIEEE, LMISTE) graduated from NIT Silchar, Assam. Completed her M.Tech from Jamia Millia Islamia, New Delhi in Electric Power Systems Mgmt and has completed her Ph.D titled " Intelligent Strategies for Distributed Generation Interface in a Smart Grid" from Jamia Millia Islamia, New Delhi. Her research interests include power systems, distributed generation, distributed energy resources,interconnection of distributed generation systems, smart grids and microgrids.

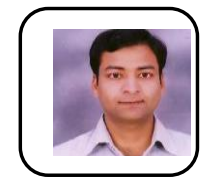

Mr. Nirmal Agarwal is Member of IEEE currently working as a Assist. Prof. in Electrical Engg. Deptt. at JSSATE Noida (UP). He graduated in Electrical Engineering from the Rajasthan University Jaipur in 2005 (With Honours). He has done M.Tech. in Advanced Power System \& Control from NIT Hamirpur (HP) in 2008. He has published/presented more than 9 papers in National/International Journals / conferences of repute. His Field of interest includes Power Sector Reforms, Facts Devices, Electrical M/c and Renewable Energy Resources.

Mr. Arun Rawat completed his B.E (Electrical Engineering) from N.I.T Silchar Assam (Assam University) in 1999. He completed his M.E (Industrial System \& Drives) from M.I.T.S Gwalior (R.G.P.V Bhopal) in 2003. He has more than 12 years of teaching experience out of which 9 years in J.S.S A.T.E Noida. His area of interest is power system transient stability.

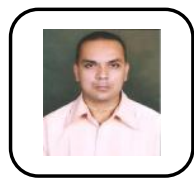

